\title{
Development of new methods for obtaining hybrid forms of spring and winter wheat with the involvement of the gene pool of wheatgrass and soybean and confirmation of the applicability of these methods in practical breeding
}

\author{
Razmakhnin E.P*., Razmakhnina T.M., Stepochkina N., Ponomarenko V.I., \\ Musinov K.K., Kozlov V.E., Surnachev A.A., Artemova G.V., Likhenko I.E. \\ Siberian Research Institute of Plant Production and Breeding - Branch of the Institute of Cytology \\ and Genetics, SB RAS, Krasnoobsk, Novosibirsk region, Russia \\ *e-mail: eprazmakh@yandex.ru
}

To increase biodiversity and improve the quality of wheat, breeders widely use the method of intergeneric hybridization of existing wheat varieties with its wild relatives, in particular, with different types of wheatgrass. Wheatgrass has the following characteristics that it is desirable to pass on to the cultivated wheat: winter hardiness, salt and drought resistance, high content of protein and gluten in the grain, resistance to diseases, low demands on soil fertility, non-lodging. As the source material for producing of new forms of winter WWHs, winter wheat cv. Filatovka and androgenic plants of wheatgrass Elytrigia intermedium were taken in our work. An original leaf nurse method of transmitting traits between different species of plants without hybridization has been developed. To produce LN-lines (lines produced by the leaf-nurse method), a winter wheat cv. Bagrationionka, and wheatgrass leaves, are taken. As a result of the application of the leaf nurse method, the appearance of plants with awned spike and elongated grains was noted. In some experiments, soybean leaves were used as a nurse. The disappearance of the awnes of the spike and the decrease in the height of plants are noted in this case. In 2017, 52 genotypes of winter WWHs and LN-lines were tested. Thirty genotypes had a significantly higher yield and quality of grain than standard cv. Novosibirskaya 40 . In the competitive test 2017-2018, 68 genotypes of WWHs and LN-lines were taken. Most of them showed high yields and resistance to lodging. No marked disease was observed. There was no damage to kernel smut. The root system of many genotypes was significantly more developed than the standard. This sign is clearly transmitted from the wheatgrass, which has a powerful root system. Analysis of the technological qualities of the grain showed that in many respects the lines created are significantly superior to the standard grade. Spring forms of WWHs were obtained by backcrossing the produced winter WWHs by spring wheat. As a result of selections in 4 generations, 32 promising non-lodging spring forms of WWHs were obtained. The yield, the size of the spike and the weight of 1000 grains of most of the accessions exceed the standard commercial cultivars. In order to expand genetic diversity and improve grain quality, the best accessions of spring WWHs were crossed between themselves and with two cvs of spring wheat Novosibirskaya 31 and Omskaya 37. Further selection was carried out in the greenhouse and in the field. In 2019, the best 129 genotypes from 419 were selected for further investigations. Thus, the obtained results prove the great promise of applying the used selection methods to obtain new valuable forms of spring and winter wheat. 